\title{
EFFECT OF PRIMARY PERCUTANEOUS CORONARY INTERVENTION ON THE INCIDENCE AND SEVERITY OF ISCHEMIC MITRAL REGURGITATION IN PATIENTS WITH ACUTE ST-ELEVATION MYOCARDIAL INFARCTION.
}

\author{
Abdel Fattah Hassan Frere MD, Soliman Mordy Ayad MD, Mohamad Mostafa \\ El Daydamony MD, Ahmed Kamel Abdel Ghany Msc* \\ Cardiology department faculty of medicine Zagazig university, National heart institute
}

\begin{abstract}
Background: Ischemic mitral regurgitation (IMR) is mitral incompetence resulting from coronary artery disease in the absence of intrinsic valve lesions. This common complication of acute myocardial infarction (AMI) (1) occurs in 15-64\% of patients after this event, (2) and is an independent predictor of future cardiovascular mortality(3). The pathophysiology of ischemic MR is complex, and its presence may be related to several underlying processes that are often difficult to separate in a given patient(4). It may result from altered ventricular geometry $(5,6,7)$, incomplete mitral leaflet coaptation, papillary muscle dysfunction and regional wall motion abnormalities (8). IMR severity is positively associated with development of heart failure after AMI.(9).Because of its complex pathophysiology and heterogeneous clinical presentation, the proper treatment of ischemic MR is often debated, and the relative utility of revascularization with and without concomitant mitral valve surgery is uncertain(4). Although primary percutaneous coronary intervention (PCI) for AMI is known to improve outcome $(10,11,12)$, and that IMR after myocardial infarction (MI) worsens outcome, (13) the effect of primary PCI on IMR incidence has not been specifically studied.
\end{abstract}

Aim of the work: To detect the impact of Primary PCI on the development and severity of ischemic mitral valve regurgitation in patients presenting with acute ST segment elevation myocardial infarction.

Patients and methods: This study included 60 patients presenting for the first time with Acute ST segment elevation myocardial infarction The patients were divided into two groups group A: Included 30 patients who were treated with primary PCI group B included 30 patients who were treated by thrombolytic therapy..All patients had echocardiography after reperfusion, during the hospital stay then reevaluation after one month period.

Results:. During hospital stay the mean LV EF in the PCI group was $46.17 \pm 7.51 \%$ while in the SK group the mean EF was $41.67 \pm 6.06 \%$.In the PCI group the mean wall motion score index during the hospital stay was $1.25 \pm 0.15$ while in the SK group it was $1.39 \pm 0.14$ with $\mathrm{P}$ value less than 0.001 . At one month follow up. In the PCI group there were 6 patients with mitral regurgitation the mean jet area was $(1.33 \pm 0.63) \mathrm{cm}^{2}$, while in the SK group there were 25 patients with mitral regurgitation the mean jet area was $(4.45 \pm 2.17)$ $\mathrm{cm}^{2}$ with $\mathrm{P}$ value $<0.0001 \mathrm{In}$ the PCI group the severity of mitral regurge was positively correlated with the age of the patient $\mathrm{P}$ value less than 0.01 ,door to needle $\mathrm{P}$ value less than 0.01 and pain to hospital times $\mathrm{P}$ value 0.04 .In the streptokinase group, the severity of mitral regurgitation was positively correlated with door to needle time delay with $\mathrm{P}$ value of 0.03 .

Conclusion: Primary PCI decreased the incidence and severity of chronic ischemic mitral regurgitation when compared with medical reperfusion in patients with acute ST segment elevation myocardial infarction.

Key words : Ischemic mitral regurgitation, Acute ST elevation myocardial infarction, Primary PCI.

* Corresponding author : Email address :Dr_Ahmedkamel@hotmail.com (Ahmed Kamel) Cardiology department,National heart institute,Cairo, Egypt

\section{INTRODUCTION}

T The mortality of STEMI is influenced by many factors, among them: age, Killip class, time delay to treatment, mode of treatment, history of prior myocardial infarction, diabetes mellitus, renal failure, number of diseased coronary arteries, ejection fraction, and treatment. (14).Several recent studies have highlighted a fall in acute and long term mortality following STEMI, in parallel with greater use of reperfusion therapy, primary percutaneous coronary intervention (primary PCI), modern antithrombotic therapy and secondary prevention treatments. (15) Randomized clinical trials comparing timely primary
PCI with in-hospital fibrinolytic therapy in high-volume, experienced centers have repeatedly shown that primary PCI is superior to hospital fibrinolysis. (16)It was the Belgian anatomist and physician Andreas Vesalius, while working in Padua, Italy, who likened the bifoliate left atrioventricular valve to a bishop's mitre, hence the term "mitral valve" (17). The physiology of the working components of the valve, its two leaflets, can be understood only when note is taken of their crucial relationships to the adjacent anatomical structures, namely, the left atrium (LA), the left ventricle (LV), the aortic valve, the papillary muscles, the tendinous cords, and the cardiac central fibrous body. 
In 1972, Perloff and Roberts(18) put forward the concept of a mitral valvular complex to underscore this essential and harmonious structural relationship. From a clinical perspective, the French surgeon Alain Carpentier introduced the paradigm of the pathophysiologic triad to better define regurgitation across the valve, pointing out that the underlying disease, the first leg of the triad, creates structural or geometric changes in the valvular apparatus, this being the second leg, which may lead to valvular dysfunction as the third leg.(19,20) Ischemic mitral regurgitation (IMR) is a common complication of coronary artery disease (CAD) and may develop in the acute or chronic phase. In chronic IMR, mitral valve (MV) leaks but the leaflets and subvalvular apparatus appear normal. Chronic MR is therefore not a disease of the valve per se, but rather a disease of the left ventricle.(21)

After the appearance of IMR, the aim of medical and/or surgical therapy is to ameliorate heart failure symptoms, and improve LV remodeling, ejection fraction and the intermediate/long-term outcome.(22)

Aim of the work To detect the impact of Primary PCI on the development and severity of ischemic mitral valve regurgitation in patients presenting with acute ST segment elevation myocardial infarction.

\section{PATIENTS AND METHODS}

This study included 60 patients presenting to the national heart institute for the first time with Acute ST segment elevation myocardial infarction according to the third universal definition of myocardial infarction which requires the presence of:

1-Symptoms of ischemia. 2-New or presumed new significant ST-segment- $\mathrm{T}$ wave (ST-T) changes (new ST elevation at the $\mathrm{J}$ point in two contiguous leads with the cut-points: $\geq 0.1 \mathrm{mV}$ in all leads other than leads V2-V3 where the

following cut points apply: $\geq 0.2 \mathrm{mV}$ in men $\geq 40$ years $: \geq 0.25 \mathrm{mV}$ in men

$<40$ years, or $\geq 0.15 \mathrm{mV}$ in women.) 3- new left bundle branch block (LBBB). (23)

\section{The patients were divided into two groups}

Group A: Included 30 patients who were treated with primary PCI.

Group B Included 30 patients who were treated with thrombolysis

\section{Inclusion criteria:}

1-Patients presenting with acute myocardial infarction for the first time.

Exclusion criteria:

Failure of reperfusion either by PCI or thrombolysis,Patients with past history of ischemic heart disease,Patients known to have rheumatic valvular heart disease. Patients with previous myocardial infarction.Patients with dilated cardiomyopathy. Patients With previous PCI or CABG.

\section{All patients were subjected to:}

\section{1-Full history taking.}

that includes the demographic data as age and gender,risk factors and the time between onset of symptoms to the first medical contact

\section{2- Full clinical examination and risk assesment.}

\section{3-Twelve lead surface ECG.}

With right ventricular leads (V3R,V4R) and posterior leads $(\mathrm{V} 7, \mathrm{~V} 8)$ when right ventricular and or posterior myocardial infarction were suspected.

\section{4-Blood samples for}

a- Cardiac enzymes b-Renal function tests

c-Random blood glucose

d- Complete blood picture

5-Reperfusion therapy was done using Primary PCI for group A or streptokinase 1.500.000 international unit intravenous infusion along one hour for group B.

\section{Definition of successful reperfusion}

Successful reperfusion is defined as

\section{GroupA:}

Reduction to residual stenosis of $<30 \%$ by balloon angioplasty or successful stent deployment at the desired position with a residual stenosis $<10 \%$, followed by Thrombolysis In Myocardial Infarction (TIMI) grade 3 flow in the infarct-related artery when using primary $\mathrm{PCI}$.

\section{Group B:}

ST-segment resolution of 50\% at 60-90 min, typical reperfusion arrhythmia, disappearance of chest pain when using fibrinolytic therapy.(24)

6-Echocardiograpy was done to all patients during the hospital stay.

7- Follow up echocardiography: The follow up echo was done to all patients of both group $\mathrm{A}$ and group $\mathrm{B}$ at least Thirty days after hospital discharge to detect left ventricular ejection fraction, wall motion abnormalities, wall motion score index and the development of ischemic mitral regurgitation.

The echo machines that were used are Philips Envisor, Philips HD7,General electric Vivid 3 and General electric Vivid S5.

\section{$\underline{\text { Assessment of Mitral Regurgitation : }}$}

Mitral regurgitation severity was evaluated during echocardiographic examination using colour Doppler flow mapping criteria according to the guidelines of the American college of cardiology and American heart association (maximal MR jet area-to-left atrial area ratio). MR severity was quantified using a 4point scale: 0 , if the percentage of maximal MR colour jet area-to-maximal left atrial area was $0 \% ; 1$ (trace MR), if the ratio was $\leq 10 \% ; 2$ (mild MR), if 
10-19\%; 3 (moderate MR), if 20-39\%; and 4 (severe $\mathrm{MR}$ ) if the ratio was $40 \%$. (25)

\section{Statistical Analysis}

Data were expressed as the mean ( \pm standard deviation) or median (interquartile range) for continuous variables, and number (\%) for categorical variables. Patient characteristics between the 2 treatment groups (PCI and non-PCI) and associations between risk factors and IMR grades will be compared using a Student's t-test for normal continuous data, a Wilcoxon rank sum test for skewed continuous data, and a chi-squared test for categorical

\section{A. Demographic data and risk factors}

Table (1) The demographic data and risk factors

\begin{tabular}{ccc}
\hline & PCI group & SK group \\
\hline Mean Age & 62.2 years & 59.23 years \\
\hline \multirow{2}{*}{ Gender } & 23 Males & 24 Males \\
\cline { 2 - 3 } & 7 Females & 6 Females \\
\hline Mean Weight & $79.67 \mathrm{~kg}$ & $79.83 \mathrm{~kg}$ \\
\hline Mean Creatinine & $1.34 \mathrm{mg} / \mathrm{dl}$ & $1.39 \mathrm{mg} / \mathrm{dl}$ \\
\hline Diabetes no. & 14 & 19 \\
\hline Hypertension no & 25 & 26 \\
\hline Dyslipidemia & 7 & 14 \\
\hline Smoking & 21 & 20 \\
\hline Family history & 5 & 6 \\
\hline
\end{tabular}

\section{B. Clinical and echocardiographic data during} the hospital stay.

\section{Myocardial area at risk}

In PCI group there were 12 patients who had anterior MI, 5 patients with extensive anterior MI,11 patients with Inferior MI and 2 patients with inferoposterior MI. In SK group there were 17 patients with anterior MI,6 patients with inferior MI, 7 patients with inferoposterior MI and there were no patients with extensive anterior MI.

2- Time between first medical contact and treatment.

In the PCI group, the mean door to balloon time was $(97.33 \pm 38)$ minutes, while in the SK group the mean door to needle time was $(39.38 \pm 11.02)$ minutes.

3. Left ventricular Ejection Fraction during hospital stay data. Data were analyzed using Statistical Program for Social Science (SPSS) version 18.0.

The following tests were done:

- Independent-samples t-test of significance was used when comparing between two means.

- Chi-square $\left(\mathrm{X}^{2}\right)$ test of significance was used in order to compare proportions between two qualitative parameters.

- Pearson's correlation coefficient (r) test was used for correlating data.

- Probability (P-value)

- P-value $<0.05$ was considered significant.

- P-value $<0.01$ was considered as highly significant.

- P-value $>0.05$ was considered insignificant. 


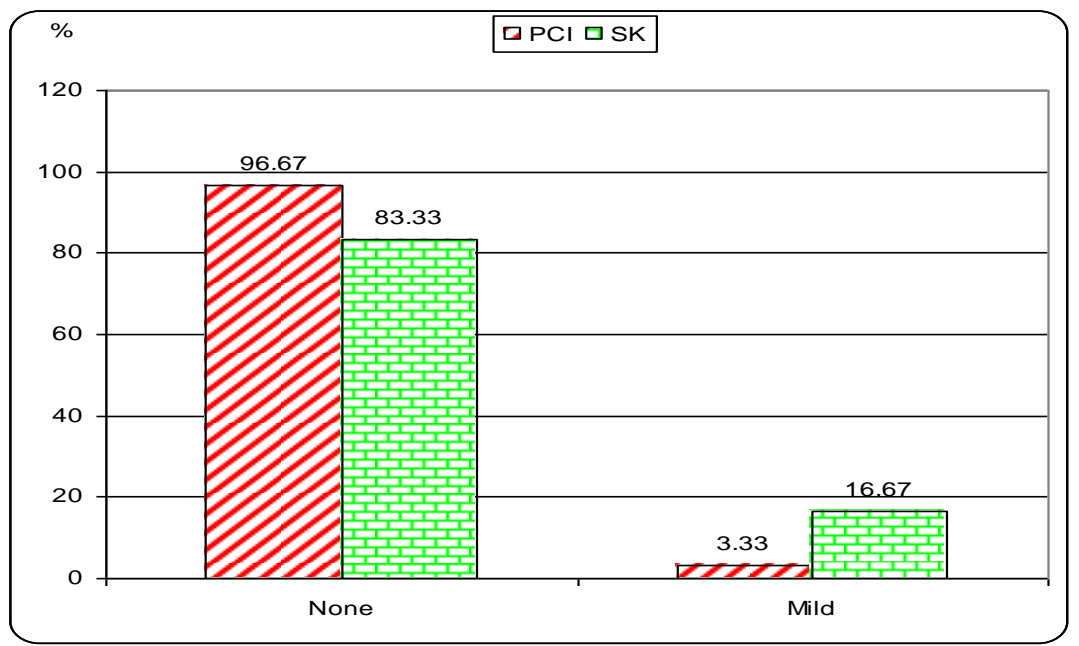

Figure (1): Relation between PCI and SK as regard presence of mitral regurgitation during hospital stay.

6.Mitral regurgitant jet area in patients who developed mitral regurgitation during hospital stay.

In the PCI group there was just one patient who had mild mitral regurgitation during hospital stay so the mean jet area was $(0.37 \pm 0.17) \mathrm{cm}^{2}$, while in the SK group there were five patients who developed mitral regurgitation while they were still at the hospital with mean jet area of $(1.19 \pm 0.057) \mathrm{cm}^{2} \mathrm{p}$ value $<0.00001$.

Table (2): Comparison between PCI and SK groups as regard mitral regurgitant jet area $\left(\mathrm{cm}^{2}\right)$ during hospital stay.

\begin{tabular}{ccccc}
\hline \multirow{2}{*}{ Groups } & \multicolumn{2}{c}{ Jet area $(\mathbf{c m 2})$} & \multicolumn{3}{c}{ t-test } \\
\cline { 2 - 5 } & Mean & $\mathbf{\pm S D}$ & $\mathbf{t}$ & p-value \\
\hline PCI & 0.37 & 0.17 & \multirow{2}{*}{7.551} & \multirow{2}{*}{$\mathbf{0 . 0 0 0 0 1}$} \\
\hline SK & 1.19 & 0.57 & & \\
\hline
\end{tabular}

C.Comparison between the two groups in the follow up echo one month after discharge.

\section{Ejection fraction}

In the PCI group the mean ejection fraction was $(53.5 \pm 5.75) \%$ while in the SK group the mean ejection fraction was $(48.83 \pm 5.83) \%$. There was highly statistically significant difference between groups, with p-value $<0.0001 \mathrm{HS}$.

Table (3): Comparison between PCI and SK groups as regarding follow up ejection fraction.

\begin{tabular}{ccccc}
\hline \multirow{2}{*}{ Groups } & \multicolumn{2}{c}{ Follow up echo ejection fraction } & \multicolumn{2}{c}{ t-test } \\
\cline { 2 - 4 } & Mean & $\mathbf{\pm S D}$ & $\mathbf{t}$ & p-value \\
\hline PCI & 53.50 & 5.75 & \multirow{2}{*}{3.124} & \multirow{2}{*}{$<0.0001$} \\
\hline SK & 48.83 & 5.83 & & \\
\hline
\end{tabular}

\section{Wall motion abnormalities in the follow up} echo

In the follow up echocardiography, 13 patients had no segmental wall motion abnormalities in PCI group versus 4 patients in SK group, there was a significant difference between the two groups $\left(\chi^{2}=6.648, p=0.01\right), 2$ patients had akinetic anterior septum in PCI group versus 2 patients in SK group, there was no significant difference between the two groups $\left(\chi^{2}=0, p=1\right)$, 7 patients had hypokinetic anterior septum in PCI group versus 13 patients in SK group, there was no significant difference between the two groups $\left(\chi^{2}=2.7, p=0.1\right), 3$ patients had akinetic inferior wall in PCI group versus 2 patients in SK group, there was no significant difference between the two groups $\left(\chi^{2}=0.218, p=0.64\right), 3$ patients had hypokinetic inferior wall in PCI group versus 2 patients in SK group, there was no significant difference between the two groups $\left(\chi^{2}=0.218, \mathrm{p}\right.$ $=0.64$ ), no patient had inferoposterior akinesia in PCI group versus 2 patients in SK group, there 
was no significant difference between the two groups $\left(\chi^{2}=2.069, \mathrm{p}=0.15\right), 2$ patients had inferoposterior hypokinesia in PCI group versus 5 patients in SK group, there was no significant difference between the two groups $\left(\chi^{2}=1.455, \mathrm{p}\right.$ $=0.228)$,

\section{Wall motion score index at the follow up}

In the PCI group the mean wall motion score index was $1.12 \pm 0.13$ while in the SK group the mean wall motion score was $1.22 \pm 0.12$, there was highly statistically significant difference between groups, with p-value $<0.001 \mathrm{HS}$.

Table (4): Comparison between PCI and SK as regard wall motion score at follow up.

\begin{tabular}{|c|c|c|c|c|}
\hline \multirow{2}{*}{ Groups } & \multicolumn{2}{|c|}{ Follow up echo wall motion score } & \multicolumn{2}{|l|}{ t-test } \\
\hline & Mean & \pm SD & t & p-value \\
\hline PCI & 1.12 & 0.13 & \multirow{2}{*}{3.092} & \multirow{2}{*}{$<0.001$} \\
\hline SK & 1.22 & 0.12 & & \\
\hline
\end{tabular}

4.Presence and severity of ischemic mitral regurgitation at the follow up

Table (5): Relation between PCI and SK as regards presence of mitral regurgitation at the follow up echo.

\begin{tabular}{cccccccc}
\hline \multirow{2}{*}{$\begin{array}{l}\text { Presence and degree of mitral } \\
\text { regurgitation in the follow up }\end{array}$} & \multicolumn{3}{c}{ PCI } & \multicolumn{2}{c}{ SK } & \multicolumn{2}{c}{ Total } \\
\cline { 2 - 7 } & No. & \% & No. & \% & No. & \% \\
\hline None & 24 & 80.00 & 5 & 16.67 & 29 & 48.33 \\
\hline Mild & 6 & 20.00 & 12 & 40.00 & 18 & 30.00 \\
\hline Moderate & 0 & 0.00 & 11 & 36.67 & 11 & 18.33 \\
\hline Severe & 0 & 0.00 & 2 & 6.67 & 2 & 3.33 \\
\hline Total & 30 & 100.00 & 30 & 100.00 & 60 & 100.00 \\
\hline $\mathrm{x} 2$ & & \multicolumn{7}{c}{27.448} \\
\hline $\mathrm{p}$-value & & \multicolumn{7}{c}{$<0.01$} \\
\hline
\end{tabular}

5.Mitral regurgitant severity (jet area) at the follow up echo

In the PCI group there were 6 patients with mitral regurgitation the mean jet area was $(1.33 \pm 0.63)$ $\mathrm{cm}^{2}$, while in the SK group there were 25 patients with mitral regurgitation the mean jet area was( $4.45 \pm 2.17) \mathrm{cm}^{2}$ with $\mathrm{P}$ value $<0.0001$

Table (6): Comparison between PCI and SK groups as regards to mitral regurgitant jet area $\left(\mathrm{cm}^{2}\right)$ at follow up echo.

\begin{tabular}{|c|c|c|c|c|}
\hline \multirow{2}{*}{ Groups } & \multicolumn{2}{|c|}{ Jet area $(\mathrm{cm} 2)$} & \multicolumn{2}{|c|}{ t-test } \\
\hline & Mean & \pm SD & $\bar{T}$ & p-value \\
\hline PCI & 1.13 & 0.63 & \multirow{2}{*}{7.563} & \multirow{2}{*}{$<0.0001$} \\
\hline SK & 4.45 & 2.17 & & \\
\hline
\end{tabular}

This table shows the difference between groups as regard jet area $\left(\mathrm{cm}^{2}\right)$ there was mean $(1.33 \pm 0.63 \& 4.45 \pm 2.17)$ respectively, there was highly statistically significant difference between groups, with p-value $<0.0001 \mathrm{HS}$.

6. Correlation between jet area in patients who had mitral regurgitation in the PCI group and
Age, Diabetes, Door to balloon time and Pain to hospital admission time.

There was highly statistically significance between jet area $\left(\mathrm{cm}^{2}\right)$ and age, door to balloon time (minutes) and statistical significant pain to door time (minutes), with positive correlation, the rest of parameters are insignificant. 
Table (7): Correlation study between Jet area $\left(\mathrm{cm}^{2}\right)$ during follow up and the age, diabetes mellitus, door to balloon (min) and pain to door parameters in PCI group Using Pearson Correlation Coefficient test.

\begin{tabular}{ccc}
\hline & \multicolumn{2}{c}{ Jet area $(\mathbf{c m} 2)$} \\
\cline { 2 - 3 } & $\mathbf{r}$ & p-value \\
\hline Age & 0.514 & $<\mathbf{0 . 0 1}$ \\
\hline Diabetes mellitus & -0.263 & 0.160 \\
\hline Door to balloon (min) & 0.470 & $<\mathbf{0 . 0 1}$ \\
\hline Pain to hospital & 0.377 & $\mathbf{0 . 0 4 0}$ \\
\hline
\end{tabular}

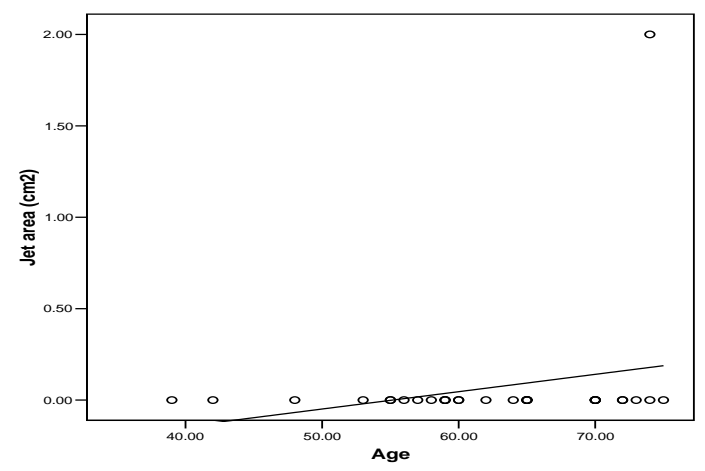

Fig. (4): Correlation between jet area (in $\left.\mathrm{cm}^{2}\right)$ at the follow up echo and age in the PCI group

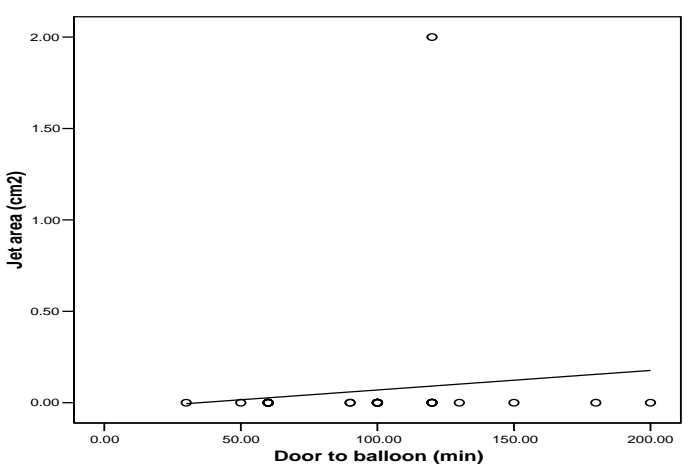

Fig. (6): Correlation between jet area( in $\mathrm{cm} 2)$ at the follow up echo and door to balloon time(in minutes) in the PCI group.

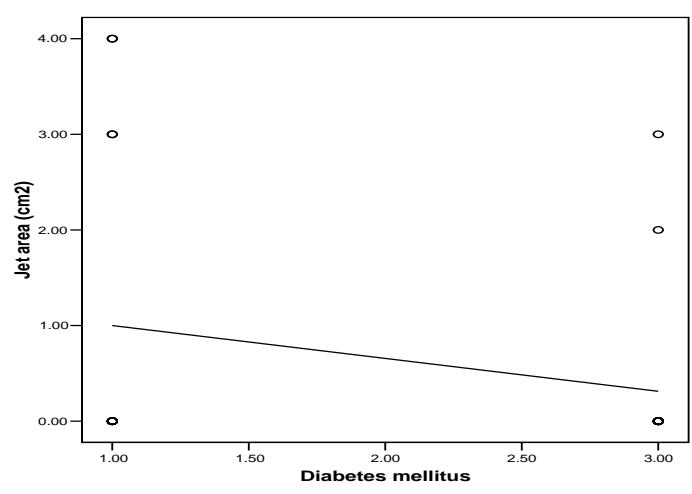

Fig. (5): Correlation between jet area( in $\mathrm{cm} 2)$ at the follow up echo and diabetes mellitus in the PCI group.

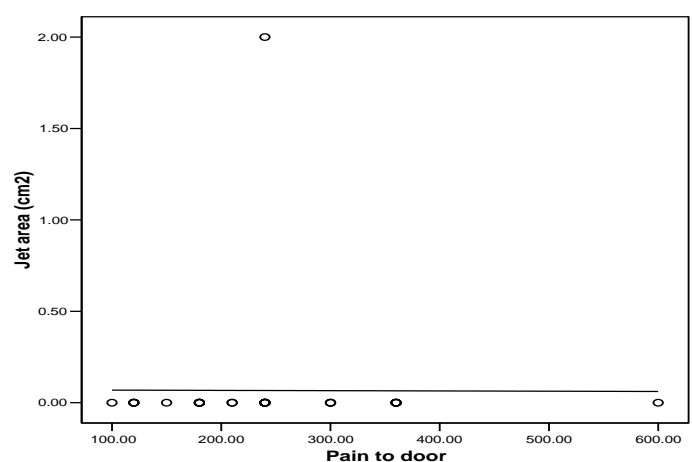

Fig. (7): Correlation between jet area( in cm2) at the follow up echo and pain to door time(in minutes) in the PCI group.

Table (8): Correlation study between Jet area $\left(\mathrm{cm}^{2}\right)$ and the age, diabetes mellitus, door to needle and pain to door parameters in SK group Using Pearson Correlation Coefficient test.

\begin{tabular}{lll}
\hline & Jet area $(\mathbf{c m} 2)$ & \\
\cline { 2 - 3 } & $\mathbf{r}$ & p-value \\
\hline Age & 0.101 & 0.601 \\
\hline Diabetes mellitus & -0.135 & 0.484 \\
\hline Door to needle & 0.399 & $\mathbf{0 . 0 3 2}$ \\
\hline Pain to hospital & 0.260 & 0.173 \\
\hline
\end{tabular}

Correlation is significant at the 0.05 


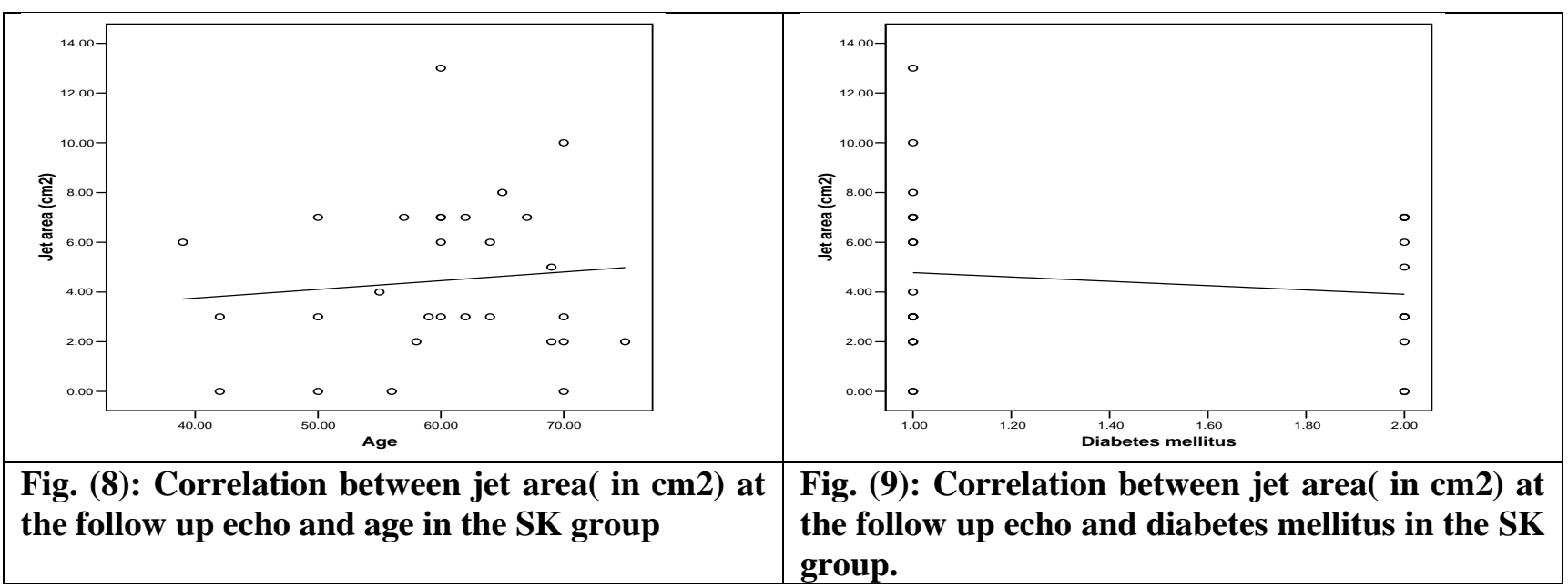

Fig. (8): Correlation between jet area( in
the follow up echo and age in the SK group

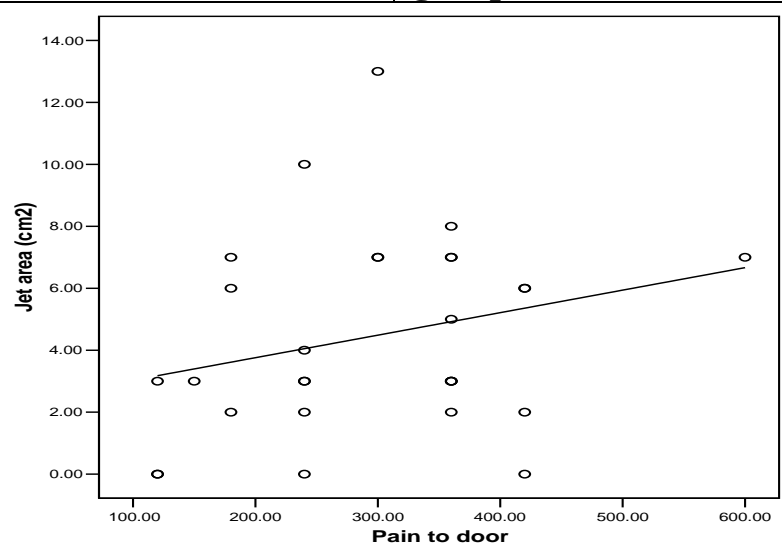

Fig. (10): Correlation between jet area( in $\mathrm{cm} 2)$ at the follow up echo and pain to door time(in minutes) in the SK group.

\section{DISCUSSION}

It is well known that MR alone is an independent factor of poor prognosis (26) and when associated with a myocardial infarction prognosis is even worse (27).Chronic IMR following MI also entails a negative impact on long-term survival (13)

In a recent registry by López-Pérez et al., (2014), they found that moderate or severe MR detected early with echocardiography was independently associated with a worse long-term prognosis in patients with STEMI treated with primary PCI.(28)

So, it appears an important issue to search for treatments or therapeutic issues that may prevent or minimize the incidence and/or severity of IMR in acute STEMI aiming to improve their prognosis. Generally, it was proved that primary PCI is more successful in preserving myocardium and decreasing complications of STEMI than thrombolysis (29).

Primary PCI of the infarct artery is preferred to fibrinolytic therapy when time-to-treatment delays are short and the patient presents to a high-volume, wellequipped center with experienced interventional cardiologists and skilled support staff (24)
Compared with fibrinolytic therapy, primary PCI produces higher rates of infarct artery patency, TIMI 3 flow, and access site bleeding and lower rates of recurrent ischemia, reinfarction, emergency repeat revascularization procedures, intracranial hemorrhage (ICH), and death (30).

In our study, initial echocardiographic results showed that patients in the thrombolysis group had a higher MR jet area by color-Doppler flow mapping.. These differences were still noteable in the follow-up echocardiography after one month. According to the follow-up echocardiographic results, there were significantly more patients with moderate or severe mitral regurgitation and significantly fewer patients without mitral regurgitation in the streptokinase group than in the PCI group.

Our results were in concordance with the study done by.Chua et al.,(2010) They found that PCI for first acute STEMI was associated with a decreased incidence of IMR compared to a medically managed group. Early, rapid coronary revascularization with PCI was strongly associated with a significant risk reduction for having moderate or severe IMR by $14.6 \% .(31)$ 
Also, similar results were found by Poh et al., (2012), as they found that both thrombolytic therapy and primary PCI were associated with decreased incidences of IMR following inferoposterior STEMI, with less incidnence of moderate and severe mitral regurgitation in patients treated by primary PCI than those treated with thtombolysis, and in those treated with thrombolysis early in the frist hour after the onset of symptoms than in those treated with thrombolysis late after the first hour has been passed.(32)

Resic et al., (2013) have compared the reperfusion effect of streptokinase versus alteplase in STEMI patients by analyzing the echocardiographic parameters including the presence and the severity of IMR. They have found that patients in the alteplase group had significantly less incidence of moderate or severe MR than those in the streptokinase group. When they took into consideration time from occurrence of chest pain to admission at clinic, the best outcomes were shown in patients who were treated with alteplase within 1.5 hour from occurrence of chest pain.(33)

In our study, and in the PCI group, we have found significant positive correlations between the jet area of mitral regurgitation by color-Doppler flow mapping and both age $(\mathrm{r}=0.514, \mathrm{p}<0.01)$, and door to balloon time $(\mathrm{r}=0.47, \mathrm{p}<0.01)$, and pain to hospital time $(r=0.377, p=0.04)$.

While in the streptokinase group, we have found only significant positive correlations between the jet area of mitral regurgitation by color-Doppler flow mapping and door to needle time $(\mathrm{r}=0.399, \mathrm{p}=$ 0.032). (

Chua et al., (2010) have found that factors associated with a significantly higher risk of positive IMR included: advanced age, Killip class $\geq 3$, increased left atrial diameter, increased LV end diastolic volume, and isolated inferior MI. When MI type (isolated inferior over isolated anterior) was used as a covariate, patients with an isolated inferior MI were 2.37 times more likely to have moderate or severe IMR than those with an anterior MI. Patients with PCI had a significantly lower incidence of positive IMR than non-PCI patients in both isolated pure anterior and inferior MI (31)

Constituents to the development of heart failure after AMI included the loss of functioning myocytes, development of myocardial fibrosis, and subsequent LV remodeling. The ensuing chamber dilatation and neurohormonal activation lead to progressive LV dysfunction (9). The presence of IMR further inflicts the hemodynamic load during a period of active LV remodeling (13).

Aronson et al., (2006) reported that there is a graded independent association between the severity of ischemic MR and the development of heart failure after $\operatorname{MI}(9)$.

Ishikawa et al., (2009) reported ischemic MR to be a common cause of congestive heart failure, caused by the process of MI remodeling(34).

As early as 1989 , coronary angioplasty was found to be useful for treating IMR in 5 patients and was associated with a favourable long-term outcome (35). Emergent PCI has been shown to improve the outcome in IMR in follow-up studies $(2,28)$

The physiopathological mechanism of ischemic MR is still under discussion, although the current preference is to explain it by a myocardial abnormality rather than by a valvular abnormality in itself, (36), which fits with the fact that STEMI patients with moderate or severe mitral regurgitation were older and had more diseased vessels, greater anterior descending artery disease, decreased LVEF, and more wall motion abnormalities (37). The benefits in mortality and cardiovascular events achieved by early invasive strategy over conservative strategy in NSTEMI patients are partly because of the reduction of incidence and severity of IMR occurring with early invasive strategy (36).Our study has shown that STEMI patients who were treated with primary PCI have less incidence and severity of IMR than those treated with streptokinase, which was found to be associated with better prognosis (Grigioni et al., 2001; Bursi et al., 2006; Levine and Schwammenthal, 2006; López-Pérez et al., 2014).So, finally we conclude that STEMI patients treated with primary PCI have less WMSI, have better $\mathrm{EF}$, and have less incidence and severity of MR. $(26,28,36)$

\section{CONCLUSION}

We conclude that primary PCI may decrease the incidence and the severity of chronic ischemic mitral incompetence if it is done as soon as possible and in a large volume PCI center.

\section{REFERENCES}

1. Levine RA, Hung J. Ischemic mitral regurgitation, the dynamic_lesion: Clues to the cure. J Am Coll Cardiol 2003; 42: 1929 - 1932.

2. Pellizzon GG, Grines CL, Cox DA, et al. Importance of mitral regurgitation in patients undergoing percutaneous coronary intervention for acute myocardial infarction: The Controlled Abciximab and Device Investigation to Lower Late Angioplasty Complications (CADILLAC) trial. J Am Coll Cardiol 2004; 43: 1368 - 1374.

3. Branco LM. Importance of mitral regurgitation in ischaemic heartdisease--more than just a bystander. Eur Heart J 2005; 26: 319-321.

4. Benjamin H, Trichon B H, Glower D, et al. Survival After Coronary Revascularization, With andWithout Mitral Valve Surgery, in Patients With Ischemic Mitral Regurgitation. Circulation 2003;108;II-103-II-110.

5. Otsuji Y, Handschumacher MD, Liel-Cohen N, et al. Mechanism of ischemic mitral regurgitation with 
segmental left ventricular dysfunction: threedimensional echocardiographic studies in models of acute and chronic progressive regurgitation. J Am Coll Cardiol 2001;37: 641-8.

6. Otsuji Y, Handschumacher MD, Schwammental E, et al. Insights from three-dimensional echocardiography into the mechanism of functional mitral regurgitation. Direct in vivo demonstration of altered leaflet tethering geometry. Circulation 1997;96:1999-2008.

7. Kono T, Sabbah HN, Rosman H, et al. Mechanism of functional mitral regurgitation during acute myocardial ischemia. J Am Coll Cardiol 1992;19:1101-5.

8. Sharma SK, Seckler J, Israel DH, et al. Clinical, angiographic and anatomic findings in acute severe ischemic mitral regurgitation. Am J Cardiol 1992;70:277-80.

9. Aronson D, Goldsher N, Zukermann R, et al. Ischemic mitral regurgitation and risk of heart failure after myocardial infarction. Arch Intern Med 2006; 166: 23622368.

10. Cannon CP. Primary percutaneous coronary intervention for all? JAMA 2002; 287: 1987 - 1989

11. Ryan TJ, Antman EM, Brooks NH, et al. 1999 update: ACC/AHA Guidelines for the management of patients with acute myocardial infarction: Executive summary and recommendations: A report of the American College of Cardiology/ American Heart Association task force on practice guidelines (committee on management of acute myocardial infarction). Circulation 1999; 100: 1016-1030.

12. Sutton A, Singh D. Early invasive strategy may reduce the risk of death and myocardial infarction after five years compared to conservative strategy. Evidencebased Cardiovasc Med 2006; 10: 44

13.Grigioni F, Detaint D, Avierinos J,et al. Contribution of ischemic mitral regurgitation to congestive heart failure after myocardial infarction. J Am Coll Cardiol 2005; 45: $260-267$

14.Mandelzweig L, Battler A, Boyko V,et al. The second Euro Heart Survey on acute coronary syndromes: characteristics, treatment, and outcome of patients with ACS in Europe and the Mediterranean Basin in 2004. Eur Heart J 2006;27:2285-2293.

15. Jernberg T, Johanson P, Held C, et al. Association between adoption of evidence-based treatment and survival for patients with ST elevation myocardial infarction. J Am Med Assoc 2011;305:1677-1684.

16. Andersen HR, Nielsen TT, Rasmussen K et al, Acomparison of coronary angioplasty with fibrinolytic therapy in acute myocardial infarction. N Engl J Med 2003;349:733-742.

17. Ho SY. Anatomy of the mitral valve. Heart 2002;88 Suppl:iv5-10.

18. Perloff JK, Roberts WC. The mitral apparatus. Functional anatomy of mitral regurgitation. Circulation 1972;46:227-39

19. Carpentier A. Cardiac valve surgery-the "French correction." J Thorac Cardiovasc Surg 1983;86:323-37.

20. Carpentier A, Chauvaud S, Fabiani JN, et al. Reconstructive surgery of mitral valve incompetence: ten-year appraisal. J Thorac Cardiovasc Surg 1980;79:338-48.
21. Lamas GA, Mitchell GF, Flaker GC, et al. Clinical significance of mitral regurgitation after acute myocardial infarction. Survival and Ventricular Enlargement Investigators. Circulation 1997;96:827-33.

22. Bolling SF, Pagani FD, Deeb GM, et al. Intermediateterm outcome of mitral reconstruction in cardiomyopathy. J Thorac Cardiovasc Surg 1998;115:381-6.

23.Thygesen K,Alpert J,Jaffe A,et al. Third universal definition of acute myocardial infarction.European Heart Journal (2012) 33, 2551-2567

24.O'Gara PT, Kushner FG, Ascheim DD, et al. 2013 ACCF/AHA guideline for the management of STElevation myocardial infarction: A report of the American College of Cardiology Foundation/American Heart Association task force on practice guidelines. Circulation 2013; 127: e362-e425.

25. Zoghbi WA, Enriquez-Sarano M, Foster E. et al. American Society of Echocardiography:Recommendations for evaluation of the severity of native valvular regurgitation with twodimension and Doppler echocardiography. J Am Soc Echocardiogr 2003; 16: 777 - 802

26. Grigioni F, Enriquez-Sarano M, Zehr KJ, et al. Ischemic mitral regurgitation. Long-term outcome and prognostic implications with quantitative Doppler assessment. Circulation 2001;103:1759-64.

27.Bursi F, Enriquez-Sarano M, Nkomo VT, et al. Heart failure and death after myocardial infarction in the community: the emerging role of mitral regurgitation. Circulation 2005; 111: 295-301.

28.López-Pérez M, Estévez-Loureiro R, López-Sainz A, et al. Long-Term Prognostic Value of Mitral Regurgitation in Patients With ST-Segment Elevation Myocardial Infarction Treated by Primary Percutaneous Coronary Intervention. Am J Cardiol 2014; 113: $907-$ 912.

29.Cox DA, Stone GW, Grines CL, et al; CADILLAC Investigators. Comparative early and late outcomes after primary percutaneous coronary intervention in STsegment elevation and non-ST-segment elevation acute myocardial infarction (from the CADILLAC trial). Am J Cardiol 2006; 98: 331-337.

30.Keeley EC, Boura JA, Grines CL. Primary angioplasty versus intravenous thrombolytic therapy for acute myocardial infarction: a quantitative review of 23 randomised trials. Lancet. 2003; 361: 13-20

31.Chua S, Hung J, Chung SY, et al. Primary Percutaneous Coronary Intervention Lowers the Incidence of Ischemic Mitral Regurgitation in Patients With Acute ST-Elevated Myocardial Infarction. Circ J 2010; 74 : 2386-2392.

32.Poh KK, Lee GK, Lee LC, et al. Reperfusion therapies reduce ischemic mitral regurgitation following inferoposterior ST-segment elevation myocardial infarction. Coron Artery Dis 2012; 23: 555-559.

33.Resic N, Durak-Nalbantic A, Dzubur A, et al. Streptokinase versus alteplase: comparison of echocardiographic parameters and postcoronarography treatment: our experience. Med Arh. 2013; 67: 322-325. 
34.Ishikawa S, Ueda K, Kawasaki A, et al. Original papillary muscle sandwich plasty for ischemic mitral regurgitation. Circ J 2009 Jul; 73(7) : 1240-2.

35.Shawl FA, Forman MB, Punja S, Goldbaum TS. Emergent coronary angioplasty in the treatment of acute ischemic mitral regurgitation: Long-term results in five cases. J Am Coll Cardiol 1989; 14: 986-991.

36.Levine RA, Schwammenthal E. Ischemic mitral regurgitation on the threshold of a solution: from paradoxes to unifying concepts. Circulation 2005; 112 : 745-758.
37.Amigoni M, Meris A, Thune JJ, et al. Mitral regurgitation in myocardial infarction complicated by heart failure, left ventricular dysfunction, or both: prognostic significance and relation to ventricular size and function. Eur Heart J 2007; 28: 326-333.

38.Tekin K, Cagliyan CE, Tanboga IH, et al. Influence of the Timing Percutaneous Coronary Intervention on Clinical Outcomes in Non-ST-Elevation Myocardial Infarction. Korean Circ J 2013; 43: 725-730 